\title{
Profile of Children's Physical Activity Behavioral in the Special area of Yogyakarta
}

\author{
Tri Hadi Karyono ${ }^{1, *}$ Abdul Alim ${ }^{1}$, Fajar Sriwahyuniati ${ }^{1}$, Risti Nurfadhila ${ }^{1}$ \\ ${ }^{1}$ Sport Coaching Department, Faculty of Sport Sciencesm \\ ${ }^{*}$ Corresponding author.Email: tri_hadi@uny.ac.id
}

\begin{abstract}
It is necessary to know the behavior of children's physical activity during the pandemic, because school activities are carried out online at home so that it can cause a decrease in children's physical activity. The purpose of this study was to determine the behavior of children's physical activity. as many as 53 participated in this study. This research is included in survey descriptive research with a quantitative approach. The data analysis instrument used was a questionnaire. data analysis using percentages. The results of data analysis showed that as many as 26 children had good physical activity behavior and 27 children had poor physical activity behavior. it can be concluded that it is still necessary to socialize good physical activity behavior in children to be able to increase the number of children with good physical activity behavior.
\end{abstract}

Keywords: Children, Physical Activity Behavioral

\section{INTRODUCTION}

Physical activity is any body movement produced by skeletal muscles and requires an expenditure of energy. Physical activity is very important in life for all ages[1]. Lack of physical activity can be one of the factors causing chronic diseases that can result in death[2]. In fact, lack of physical activity has an impact on the risk of heart disease, diabetes and cancer[3]. In fact, most of the causes of premature death are related to lack of physical activity. But unfortunately, many are still not aware of the importance of physical activity. Most of the physical activity in early childhood has a low intensity, many children are less physically active, and even physical activity decreases with age[4]. Decreased physical activity occurs in the group of early childhood. Physical activity at the age of children and adolescents is very important because if the level of physical activity is low in early childhood, it will be associated with poor physiological status. Increasing physical activity and reducing sedentary habits can improve the health and well-being of early childhood. Physical activity is positively associated with various psychological, cognitive and cardio-metabolic outcomes of children, this is very important for developing healthy lifestyle habits from an early age[5]. Although the reasons for this low level of physical activity are not well understood, research conducted on 65 children in New
York showed that children's motor skills may be an appropriate target for increasing physical activity at an early age[4]. Previous research proves that motor skills and physical activity can contribute to early childhood health. As research conducted by [6] proves that delays in motor skill development have been associated with lower physical abilities.

Therefore, the purpose of this study was to determine and map the physical activity behavior of children, especially in the special area of Yogyakarta. during the pandemic where learning is using online so that it will also increase the use of gadgets in children which can reduce physical activity. Therefore, it is necessary to know that physical behavior is important to do.

\section{METHOD}

\subsection{Participant}

The respondents of this study were 53 children in the Yogyakarta area. There are 48 males and 5 females. 8 people 7-9 years old and 45 people 10-12 years old.

\subsection{Research Method}

The research method used in this study is a descriptive survey with a quantitative approach. 


\subsection{Procedures}

In this study, researchers took several steps to then obtain research data. After determining the problem and population, the main thing that the researcher and the team did was to conduct a survey to preschool, kindergarten and elementary schools in the Special Region of Yogyakarta to find the children needed as samples, namely children aged 5-12 years. Furthermore, the researchers conducted socialization with the school and parents/guardians of students who would be sampled regarding this research in detail. When the parents/guardians of the sample have understood and agreed, the guardian of the sample honestly and truthfully filled out the consent form or concern form stating their agreement to participate in this study. Measurement of daily activity samples will fill out a questionnaire measuring physical activity.

\subsection{Data Analysis}

The data analysis of this research used percentage analysis. Percentage analysis is used to find out the percentage of the number of children in relation to physical activity behavior

\section{RESULT AND DISCUSSION}

\subsection{Result}

This study was followed by 53 respondents consisting of 48 male respondents and 5 female respondents. The following are the age characteristics of the respondents in this study.

Table 1. Characteristic of The Respondence

\begin{tabular}{|c|c|c|c|}
\hline Age & Male & Female & Total \\
\hline $7-9$ & 8 & 0 & 8 \\
\hline $10-12$ & 40 & 5 & 45 \\
\hline
\end{tabular}

The results of this study indicate that in general the behavior of children's physical activity in the Special Region of Yogyakarta has not been well distributed. The results of the study can be seen in the following table:

Table 2. Data Analysis Result

\begin{tabular}{|c|c|c|}
\hline Category & Frequency & Percentage (\%) \\
\hline good & 26 & 49 \\
\hline poor & 27 & 51 \\
\hline
\end{tabular}

Based on table 2, it can be concluded that good physical activity behavior is not evenly distributed among all children. there are still $51 \%$ of children who have poor physical activity behavior.

\subsection{Discussion}

The results of this study indicate that there is not even distribution of good physical activity behavior in children in the Yogyakarta area. This is indicated by the presence of $51 \%$ of children who have poor physical activity behavior. This is a problem that needs an immediate solution. because physical activity behavior can have an impact on children's motor development.

The COVID-19 pandemic has had a major impact on the way children play. Children experience a transition from offline to online. In the online era there are two types of children's play; The first is children who feel bored and tired of playing at home because they are not able to provide playing satisfaction. Children are forced to play outdoors with their friends without paying attention to the health protocols that should be obeyed. Even though the government has appealed to the public to carry out social restrictions and reduce activities outside the home [7]. As a result, children become lazy because they have too much playing time and are not controlled. While the second is children who experience limitations in channeling their energy in playing activities.

Study conducted by [8] stated that during the COVID-19 pandemic, children lack physical activity, rarely play outside, sit more with digital screen-based activities and spend more time sleeping than before COVID-19 social restrictions. Other research suggests that girls use social media and sleep more than boys. This is evidenced by the increase in the use of social media, which is $95 \%$, which causes a reduction in outdoor play. Playing indoors or outdoors during the COVID-19 pandemic can actually contribute to or even worsen a child's health. However, outdoor play has more physical activity, less leisure time, adequate sleep, improves mental health and increases immunity.

Prevention of unhealthy behavior during nationalscale social restrictions, health promotion messages must be balanced with disease prevention messages. So that not only the slogan "just stay at home" but "get out of the house and play" can also be achieved. The encouragement and involvement of parents is very important in enforcing clean and healthy living behavior [9]. Some literature states that parental support is the main factor for children's development, even though parents experience stress due to the declining economy and have to be teachers as well as parents at home during COVID-19. Thus, physical activity and playing outside the home with guidance and cooperation between teachers, parents and children can be an effort to improve children's health. In line with research [10] states that parents in Canada have ways that they can use in their free time to develop or renew hobbies such as planning family recreation time that can reduce children's mental health during COVID-19 social restrictions. Because many families think that the COVID-19 social restriction is a trauma so that they lock themselves and their children at home which causes a decline in health and mental illness[11]. By 
playing outdoors with active physical activity can reduce the burden of health and mental illness.

Based on this explanation, it can be concluded that parents in responding to the COVID-19 social restrictions need to encourage and engage in creative and safe active play activities for children. Parents and children together do a new hobby or fun activity outside the home while still adhering to health protocols. Children are encouraged to play outdoors regularly [10]. The role of parents in guiding and regulating children's routines such as time to play gadgets, sleep, wake up and quality time to be with family through direct play. The government also needs to provide space for people to cycle, walk and run and maintain child-friendly open playgrounds.

\section{CONCLUSION}

The results of data analysis show that there is not even distribution of good physical activity behavior in children in the special area of Yogyakarta. this can be caused by several factors including the pandemic and technological advances. The factors that cause the decrease in children's physical activity need to be reviewed again to reduce the risk of poor physical activity behavior.

The role of parents in guiding and regulating children's routines is important such as time to play gadgets, sleep, wake up and quality time to be with family through direct play. The government also needs to provide space for people to cycle, walk and run and maintain child-friendly open playgrounds.

\section{REFERENCES}

[1] M. S. Tremblay, J. W. Inman, and J. D. Willms, "The relationship between physical activity, selfesteem, and academic achievement in 12-year-old children," Pediatr. Exerc. Sci., vol. 12, no. 3, pp. 312-323, 2000, doi: 10.1123/pes.12.3.312.

[2] WHO, Global Recomendations on Pysical Ativity for Health. Switzerland: WHO, 2010.

[3] O. H. Zahrt and A. J. Crum, "Effects of physical activity recommendations on mindset, behavior and perceived health," Prev. Med. Reports, vol. 17, no. December 2019, p. 101027, 2020, doi: 10.1016/j.pmedr.2019.101027.

[4] B. H. Wrotniak, L. H. Epstein, J. M. Dorn, K. E. Jones, and V. A. Kondilis, "The relationship between motor proficiency and physical activity in children," Pediatrics, vol. 118, no. 6, 2006, doi: 10.1542/peds.2006-0742.

[5] B. Del Pozo-Cruz et al., "Joint physicalactivity/screen-time trajectories during early childhood: Socio-demographic predictors and consequences on health-related quality-of-life and socio-emotional outcomes," Int. J. Behav. Nutr. Phys. Act., vol. 16, no. 1, pp. 1-13, 2019, doi: 10.1186/s12966-019-0816-3.

[6] D. Schraw, G., \& Robinson, Assessment of Higher Order Thinking Skills. Current Perspectives on Cognition, Learning and Instruction. IAPInformation Age Publishing, Inc., 2011.

[7] J. Hamzelou, "Wuhan coronavirus may have been transmitted to people from snakes," New Scientist, 2020.

[8] C. Wang, P. W. Horby, F. G. Hayden, and G. F. Gao, "A novel coronavirus outbreak of global health concern," Lancet, vol. 395, no. 10223, pp. $470-473, \quad 2020, \quad$ doi: $\quad 10.1016 / \mathrm{S} 0140$ 6736(20)30185-9.

[9] S. N. Vikra, "Karakter Generasi Milenial Dalam Prespektif Hamka," Banda Aceh, 2020.

[10] L. de Lannoy, R. E. Rhodes, S. A. Moore, G. Faulkner, and M. S. Tremblay, "Regional differences in access to the outdoors and outdoor play of Canadian children and youth during the COVID-19 outbreak," Can. J. Public Heal., vol. 111, no. 6, pp. 988-994, 2020, doi: 10.17269/s41997-020-00412-4.

[11] D. G. I. Viscuso and D. E. Mangiapane, "Pandemic Covid-19: Psychodynamic analysis of a global trauma. Clinical considerations pre $\backslash$ post Lock down.," J. Med. Res. Heal. Sci., vol. 3, no. 6, pp. 976-990, 2020, doi: 10.15520/jmrhs.v3i6.194. 